\title{
sobre: La condición intelectual. Informe para una academia, de Raúl Rodríguez Freire. santiago de chile: Mímesis, 2018.
}

\author{
DANIELA CÁPONA GONZÁLEZ Universidad de Chile, Chile / dcapona@gmail.com
}

\begin{abstract}
...lo que son coincide, por consiguiente, con su producción, tanto con lo que producen como con el modo cómo producen. Lo que los individuos son depende, por tanto, de las condiciones materiales de su producción.
\end{abstract}

Marx y Engels. La ideología alemana.

Marx y Engels escribieron esta sentencia en la Ideología alemana, obra en la cual, a juicio de Etienne Balibar, el ser o la realidad de los hombres se identifica con su producción, fusionando los antaño sentidos antagónicos que portan la poiesis y la praxis (47), es decir la producción servil de cosas, y aquella referida a la propia perfección, la producción de sí mismo. Si bien Rodríguez Freire no hace alusión a esta idea de Marx, sí da sentido a su libro, pues pone el ejercicio intelectual del saber, a sus agentes, ante el desafío de comprender esta fusión en su propio trabajo en su condición actual, es decir, bajo su proceso de neoliberalización. Para lograr esto, el autor nos retrotrae no solo a Marx, sino también a Benjamin, con quien comparte el llamado a pensar desde la exigencia de reflexionar sobre la posición del autor (el intelectual) dentro del proceso de producción (124), a partir del texto «El autor como productor», cuestión que si bien aparece en las últimas páginas del libro, podría decirse que constituye nuclearmente la hipótesis de la obra. Por ello Marx, y un cierto Marx, con el cual disiente en ocasiones, se hace presente para formular la cuestión transversal para este Informe para una academia: ¿qué tipo de trabajo es el intelectual?; ¿produce valor, un cierto tipo de valor o no lo produce?; ¿se inserta este en la cadena productiva de la forma valor misma, como sujeto automático? Por este motivo, el libro comienza con un diagnóstico de la llamada condición intelectual, desde la crítica ácida y argumentativamente justificada, respecto del rol del trabajo intelectual en el marco del neoliberalismo, cuando este no se resiste a su dominación, en su denominación cruda de "capital humano». Ejercicio escriturario que no se esconde en el impersonal «el» o «se», sino que pone el ejercicio del propio autor dentro de esa crítica, dentro de ese rol; no se trata de ese «ellos» separado, sino de un «ellos» en los cuales también él se reconoce. En

Para citar este artículo: Cápona González, Daniela (2019). Sobre: La condición intelectual. Informe para una academia, de Raúl Rodríguez Freire. El taco en la brea, 9 (diciembre-mayo), 122-125. Santa Fe, Argentina: UNL. DOI: 10.14409/tb.viig.8209 
este sentido, constituye un llamado al reconocimiento, en cuanto intelectuales, profesores, como partícipes - sea desde una lógica pasiva como activa— de las prácticas descritas, como apéndices del capital, si, y solo si, este tipo de trabajo produce algún tipo de valor como sujeto automático, trabajo vivo como capacidad de trabajar, de producir plusvalía.

A partir de esto, el meollo de este Informe reside en una apropiación y articulación del pensamiento marxista, de sus categorías en un análisis claro, conciso y oportuno, en lo que respecta a la teoría del valor y su relación con el trabajo del intelectual, tanto si este fuese abstracto - y por ende sujeto a procesos de valorización y autovalorización-, como si fuese improductivo, retornando a la figura del productor directo. Análisis nutrido desde distintas perspectivas, como la de Postone, Kurz, Jappe - marcadamente desde la línea de Krisis -, pero que se posiciona desde un nuevo punto de vista que Marx no trabaja debido a sus condiciones históricas, en tanto que en su época el rol del trabajo intelectual no solo era menor, sino que no se insertaba directamente en la producción de valor, de allí que no pudiese prever que este trabajo podría ser consumido por el capital, cuestión que el autor reconoce. Aquí es donde radica la novedad del ejercicio propuesto, que es precisamente cómo pensar una articulación entre el trabajo del intelectual y la teoría del valor desde la consideración de su producto. Ejercicio un tanto peligroso, no solo por el análisis especulativo que debe realizarse desde Marx, sino porque enfrenta al intelectual a una realidad que, en su calidad de crítico, no se quiere develar, y es que él también se constituye como un apéndice del neoliberalismo, en cuanto él también deviene capital variable, en virtud del trabajo abstracto — categoría para Rodríguez, tal como para Postone y Krisis, no obsoleta—, es decir, una categoría económica que está al servicio de la producción de plusvalía. Pero el trabajo intelectual, cabe recordar, y cuestión que Raúl Rodríguez recuerda, no es inmaterial, y recalca, «ningún trabajo es inmaterial» (127), elaborando una crítica a la ya famosa y reiterativa apelación al General Intellect, en el llamado fragmento de las máquinas de los Grundrisse, cuyos mayores exponentes son Negri, Lazzarato y Virno, en los cuales vería la inocencia de un pensamiento que no se atiene directamente al texto de Marx, sino que además se deja llevar por intuiciones que le otorgan un sentido redentor. Rodríguez Freire, por el contrario, ve que lo que Marx recalca allí es «la imbricación entre pensamiento y técnica, entre cerebro y mano, "hombre" y "naturaleza", y ello con el fin de desontologizarlo» (136-137), desde donde concluye «no es posible pensar el trabajo intelectual sin la materialidad del cuerpo y los órganos que éste secreta» (137). La crítica apunta al hecho que, la relevancia al trabajo intelectual vela la importancia del trabajo material del cual depende, «ocultándose lo que Evando Nascimiento, a partir de Helio Oiticica, llamará i-materialidad, real y virtual, material e inmaterial, a la vez» (140). Ahora bien, si se sigue el argumento anterior, se puede decir, siguiendo aquí a David Harvey, que «el capital circula, como si dijéramos, a través del cuerpo del trabajador como capital variable y por tanto lo convierte en un mero apéndice de la circulación del propio capital» (Harvey:180). El cuerpo nunca está disociado de su producción, de allí el énfasis en poiesis y praxis, en la aseveración de Marx en los Manuscritos de economía y filosofía de 1844 de que el hombre (su cuerpo, su sensibilidad) es producto de un trabajo histórico social, la apelación a la naturaleza inorgánica, podríamos también mencionar aquí dentro de las precisas referencias que Rodríguez Freire nos entrega, el trabajo sobre la producción estética de la sensibilidad y su importancia en Marx, de Carlos Casanova (2016), y los argumentos de Leroi-Gourhan y Bernard Stiegler, que con sumo cuidado indican el rol cardinal del cuerpo en la producción. El gran problema que articula el libro es por lo tanto, el cuestionamiento respecto a si el trabajo intelectual (siempre material) 
es abstracto y productivo, o bien improductivo, con matices en esta última definición, concebido como un retorno del productor directo. Este problema que claramente es irresoluble, indica a los intelectuales como actores de las derivas de sus «productos». En este sentido, la lectura que se nos propone no cae en un catastrofismo ni en la ingenuidad positiva, pues si bien reconoce que la dominación que ejerce el neoliberalismo, si bien es extendida (y también desterritorializada), no es total, y no puede serlo, a pesar de todos los intentos de mercantilización, financiarización y privatización que pretenda en su expansión geográfica planetaria. Es desde esa abertura que invita a pensar, nuevamente, sin ingenuidad, pero tampoco con un optimismo redentor, sino desde la experiencia y el análisis riguroso. De allí que vea en la teoría del valor una forma de entrada distinta al problema, que le permite postular el trabajo intelectual — de cierto modo improductivocomo un modo de resistencia a los procesos de valorización y autovalorización que constituyen la forma-valor del sujeto automático, y por ende, como trabajo servil hacia el capital, como un factor que contribuye no solo a su reproducción, sino también a su proceso de acumulación. Solo de este modo, bajo este punto de análisis, y de allí la recurrencia a Jappe y a Kurz, puede afirmar que «la producción intelectual constituye, por tanto, una resistencia al proceso de valorización. Empero, esta es solo una posibilidad por cuya acontecimentalidad se debe trabajar, esquivando lo que más se pueda la axiomatización del capital en el intento» (114).

Ahora bien, si se mencionaba anteriormente la referencia al texto de la Ideología alemana de Marx, que el autor no indica en su obra, es porque precisamente conduce a posicionarse en esa dicotomía siempre conflictiva de la identidad entre nosotros como hombres-mujeres y nuestras producciones, enfatizando, y del modo en cómo las producimos. Esta sentencia, podría bien funcionar como epígrafe de este Informe. Si bien los lineamientos de esta tensión no siempre están en nuestro poder, en la medida en que la Universidad misma se ha regimentado bajo políticas neoliberales que, deben ser cumplidas para asegurar el puesto de trabajo (publicaciones indexadas, índice h5, libros best seller, y tantas más), como bien menciona el autor, hay una forma del trabajo intelectual que se postula a modo de resistencia a esta regimentación económico-política. Esa sería precisamente la imputación a la que lleva este libro, a preguntarse cómo se puede reconfigurar e impugnar el espacio universitario desde el trabajo intelectual, y por ello es que el mismo libro es ya un ejercicio político de resistencia, tanto la obra en sí misma como la apuesta editorial de Mimesis, la misma forma experimental en que está escrito y en donde las páginas disocian la lectura de izquierda a derecha, de arriba abajo, un ejercicio de escritura que no solo es del autor, sino también del lector, que disocia la imagen del libro estereotipado y de la escritura académica, e invita a pensar la misma escritura desde una perspectiva alternativa que pugna contra la estandarización. Un libro que, con osadía e intrepidez argumentativa, expone una realidad que no se quiere evidenciar, que se vela en actividades pomposas en busca de reconocimiento, de la marca y la firma, en la búsqueda de autovalidación pública. Rol que, supuestamente el intelectual, por la cualidad de su trabajo, debiese mantener abstemio no por negar el ego, sino por no fortificarlo, por no escindir su trabajo de la idea de lo común y social a lo cual supuestamente pretende.

Para concluir, el ejercicio de reflexión entre Marx y Benjamin, que ofrece Rodríguez Freire, es uno que con-mueve a una acción común, a una actividad; un libro que cuestiona las formas en que se realiza el trabajo intelectual, y por ende, al intelectual mismo en su calidad de trabajador. No es un libro sobre Marx, o sobre Benjamin, es un ejercicio filosófico que pone en obra al pensamiento, desde las categorías de los mentados filósofos, para incurrir en una nueva reflexión. 
Este Informe pone en evidencia en primer lugar, una realidad no visible desde los movimientos sociales que desde hace ya años en Chile, intentan reivindicar la educación en sus distintos aspectos, que no es solo la introducción de los espacios educacionales en la lógica de la mercantilización —abogando en contra, en este sentido, por la calidad y gratuidad de esta-, sino el rol directo de los intelectuales en ese proceso, no como agentes pasivos sino como activos de tal operación. De allí que este diagnóstico sirva para pensar y comprender —especialmente hoy, especialmente acá, en Valparaíso, pero también en el contexto general de las universidades - por qué y cómo opera el mundo universitario académico que precisamente se busca reivindicar. Por ello, se puede pensar, para finalizar, que este llamado hace sintonía y eco con el ya realizado por Marx en la ya famosa onceava tesis sobre Feuerbach: «Los filósofos — podríamos decir aquí, los intelectuales — se han limitado a interpretar el mundo de distintos modos; de lo que se trata es de transformarlo» (667).

\section{Bibliografía}

Balibar, E. (2000). La filosofia de Marx. Buenos Aires: Nueva visión.

Casanova, C. (2016). Estética y producción en Karl Marx. Santiago de Chile: Metales Pesados.

Harvey, D. (1990). Los límites del capitalismo y de la teoría marxista. México: Fondo de Cultura Económica.

Marx, C; Engels, F. (1970). La ideología alemana. Barcelona: Pueblos Unidos/Grijalbo. 